\title{
Patient Satisfaction with Dental Appearance and Related Factors- A Cross Sectional Study
}

\begin{abstract}
Marzieh Karimi Afshar ${ }^{1}$, Ali Eskandarizadeh², Molook Torabi³, Mohammad Javad Mousavi', Iman Mohammadzadeh ${ }^{5}$
${ }^{1}$ Department of Orthodontics, Kerman Social Determinants on Oral Health Research Center, School of Dentistry, Kerman University of Medical Sciences, Kerman, Iran. ${ }^{2}$ Department of Operative Dentistry, Kerman Social Determinants of Oral Health Research Center and Oral and Dental Diseases Research Center and Kerman, School of Dentistry, Kerman University of Medical Sciences, Kerman, Iran. ${ }^{3}$ Department of Maxillofacial Pathology, Kerman Social Determinants of Oral Health Research Center and Oral and Dental Diseases Research Center and Kerman, School of Dentistry, Kerman University of Medical Sciences, Kerman, Iran. ${ }^{4}$ Department of Maxillofacial Pathology, School of Dentistry, Kerman University of Medical Sciences, Kerman, Iran. ${ }^{5}$ Department of Maxillofacial Pathology, Oral and Dental Diseases Research Center Kerman University of Medical Sciences, Kerman, Iran.
\end{abstract}

\section{ABSTRACT}

\section{BACKGROUND}

Dental appearance is one of the most important determinants of facial attractiveness and has a key role in social interactions. This study aimed to assess the satisfaction with dental appearance and the factors influencing this satisfaction among the patients attending dental clinics in Kerman, Iran (2017).

\section{METHODS}

This cross-sectional study was conducted on 329 patients who were attending dental clinics in Kerman. Data were collected by a questionnaire consisting of demographic information (gender, age, education level, smoking, economic condition) and 14 questions about dental aesthetics. The collected data was analysed in SPSS 22 and chi square test. The significance level was considered to be $\mathrm{p}<0.05$.

\section{RESULTS}

Of the respondents, $52.3 \%$ (172) were female, $69.60 \%$ (229) were satisfied with their dental appearance, and $61.70 \%$ (203) preferred tooth whitening as the cosmetic treatment for improving dental appearance. The mean score of satisfaction with dental appearance was $9.77 \pm 3.42$ from 14 . There was a significant correlation between the economic condition and the mean satisfaction score. A significant correlation was also observed between gender and general satisfaction with dental appearance. Satisfaction score had a significant correlation with age, smoking, and economic condition.

\section{CONCLUSIONS}

Tooth whitening was the most preferred method for improving dental appearance. Older people were significantly less satisfied with their dental appearance and people with better economic conditions were significantly more satisfied with their dental appearance. To ensure patient satisfaction with cosmetic treatments, clinicians should gain a better understanding of patients' perceptions, desires, and apprehensions in regard to dental appearance.

\section{KEY WORDS}

Dental Appearance, Satisfaction, Dental Aesthetics, Treatment, Beauty, Cosmetic Dentistry
Corresponding Author:

Molook Torabi

Kerman Social Determinants of Oral Health Research Center and Oral and Dental Diseases Research Center and Kerman and Department of Maxillofacial Pathology, School of Dentistry, Kerman University of Medical Sciences, Kerman, Iran.

E-mail: m.torabi.p@gmail.com

DOI: 10.14260/jemds/2019/771

Financial or Other Competing Interests: None.

How to Cite This Article: Afshar MK, Eskandarizadeh A, Torabi M, et al. Patient satisfaction with dental appearance and related factors- a cross sectional study. J. Evolution Med. Dent. Sci. 2019;8(48):3569-3574, $10.14260 /$ jemds $/ 2019 / 771$

Submission 14-09-2019, Peer Review 11-11-2019, Acceptance 18-11-2019, Published 02-12-2019. DOI: 


\section{BACKGROUND}

Dental appearance is one of the main features that determine the attractiveness of our face and plays a key role in our social interactions. Dental appearance is generally determined by the colour, shape, location, alignment, and occlusion of the teeth, especially the anterior teeth, and the quality of dental restorations.(1) However, this concept also depends on cultural, economic, and social factors and personal preferences, as a certain appearance may be considered desirable by one person or culture and undesirable by others. The perception of beautiful teeth also varies with gender and education. It has been shown that women are more sensitive to dental appearance than men and the importance given to dental appearance increases with age and education level.(2)

Since people generally prefer pristinely white teeth, the colour of teeth is one of the most important determinants of people's satisfaction with their dental appearance.(1,3) It has been shown that having white teeth is positively correlated with increased sociability, mental ability, psychological adaptability, and communication skills.(4) Conversely, having untreated tooth decay, poor anterior tooth restoration, and lack of anterior teeth results in dissatisfaction with dental appearance. $(1,2,5,6)$ Satisfaction with dental appearance has been estimated to be $79.4 \%$ in Nigeria,(7) $67.6 \%$ in Jordan,(8) $71.1 \%$ in Turkey, ${ }^{(9)}$ and $47.2 \%$ in Malaysia. In a study by Maghaireh et al., they found that most people were not satisfied with their tooth colour and the most sought-after treatment was tooth whitening. Also, they reported that women were significantly more likely to seek cosmetic and orthodontic restorations.(10) In a study by Tin-Oo, satisfaction with tooth colour was significantly lower in women and teeth whitening was the most preferred treatment.(11)

Hassel et al. reported a high degree of satisfaction with dental appearance among German elderly and concluded that both function and beauty should be considered in dental treatments. ${ }^{(12)}$ Given the importance of cosmetic dentistry as a major branch of dentistry and the increasing demand for teeth whitening treatments, anterior tooth restorations, and orthodontic treatments of anterior veneers to improve dental appearance, this study attempted to assess the satisfaction with dental appearance and the tendency to undergo cosmetic dental treatments among the patients attending dental clinics in Kerman, Iran.

\section{METHODS}

A descriptive cross-sectional study was performed on the patients attending dental clinics in Kerman. The sample size was 384, which was determined using the sample size formula-

$\left(n=\frac{z^{2} * p(1-p)}{d^{2}}\right)$ with

$\mathrm{z}=1.96, \mathrm{~d}=0.05$ and $\mathrm{p}=0.5$.

After obtaining the necessary permits and gaining verbal consent, the questionnaire was administered with the assistance of a senior student who was trained to guide the patients and answer their questions when necessary. For sampling, the city was divided into five regions: north, south, east, west, and center (Under the assumption that they have different degrees of affluence) and two clinics were selected from each region. The assistant visited the selected clinics three days a week and administered the questionnaire to random patients face to face. The approximate response time was about 10 minutes. This process continued until reaching the desired sample size.

The data collection instrument was a questionnaire made by the researchers based on similar studies, which consisted of demographic questions (Gender, age, education level, economic condition, and smoking) and a self-report section with 14 closed-ended questions about orthodontic problems, satisfaction with the general shape and appearance of teeth, inclination to undergo different cosmetic dental treatments, and the effect of dental appearance on self-esteem and smile. People who had undergone or were undergoing orthodontic treatment, people who had received any cosmetic treatment (e.g. laminate, crown, composite veneer), and people under the age of 18 were not included in the study. The validity of the questionnaire was assessed by dental professionals and verified with a coefficient of 0.98 . For reliability assessment, the questionnaire was administered to a group of 20 patients twice with a one-week interval. Using the ICC method, the reliability of the questionnaire was calculated to 0.83 .

After collecting the completed questionnaires, the data were coded and entered into SPSS version 22, where they were analysed using the descriptive statistics tools including mean, standard deviation, frequency, and percentage frequency and chi square test at the significant level of $\mathrm{p}<0.05$. It should be noted since incomplete questionnaires and those with incoherent answers were excluded, the final statistical analysis was performed on the data of 329 questionnaires. During the data collection phase, participants were duly ensured about the voluntary nature of participation and the confidentiality of their identity and responses.

The proposal of this study was approved by the Ethics Committee of Kerman University of Medical Sciences with the code IR.KMU.REC.1395.777.

\section{RESULTS}

Of the 329 people who completed the questionnaire correctly, $172(52.3 \%)$ were women and $157(47.7 \%)$ were men. The majority of the respondents were in the age group of 21-25 years $169(41.4 \%)$. The plurality of the respondents 131 (39.8\%) had a bachelor's or higher degree. The demographic information of the respondents is presented in Table 1. The frequency of responses given to the questions about satisfaction with dental appearance is illustrated in Figure 1. As can be seen, 229 [69.60\%] of the respondents were generally satisfied with their dental appearance, 109 [33.1\%] of them had unappealing restorations in the anterior teeth, and $52.27 \%$ of them were satisfied with their tooth colour.

Relationship between the satisfaction with dental appearance and the satisfaction with tooth colour and demographic variables are presented in Table 2. 


\begin{tabular}{|c|c|c|c|}
\hline \multicolumn{2}{|c|}{ Variables } & Number & Percent \\
\hline \multirow{2}{*}{ Sex } & Male & 157 & 47.7 \\
\hline & Female & 172 & 52.3 \\
\hline \multirow{5}{*}{ Age Group(year) } & $>20$ years & 97 & 29.5 \\
\hline & $21-25$ years & 169 & 41.4 \\
\hline & 26-30 years & 48 & 14.6 \\
\hline & $31-36$ years & 7 & 2.1 \\
\hline & $>37$ years & 8 & 2.4 \\
\hline \multirow{4}{*}{ Educational Level } & diploma & 55 & 16.7 \\
\hline & Higher than diploma & 8 & 2.4 \\
\hline & License & 123 & 37.4 \\
\hline & Higher than License & 8 & 2.4 \\
\hline \multirow{4}{*}{ Economic Status } & bad & 16 & 4.9 \\
\hline & Average & 161 & 48.9 \\
\hline & good & 139 & 42.2 \\
\hline & Excellent & 13 & 4.0 \\
\hline \multicolumn{4}{|c|}{ Table 1. Demographic Variables of Participants } \\
\hline
\end{tabular}

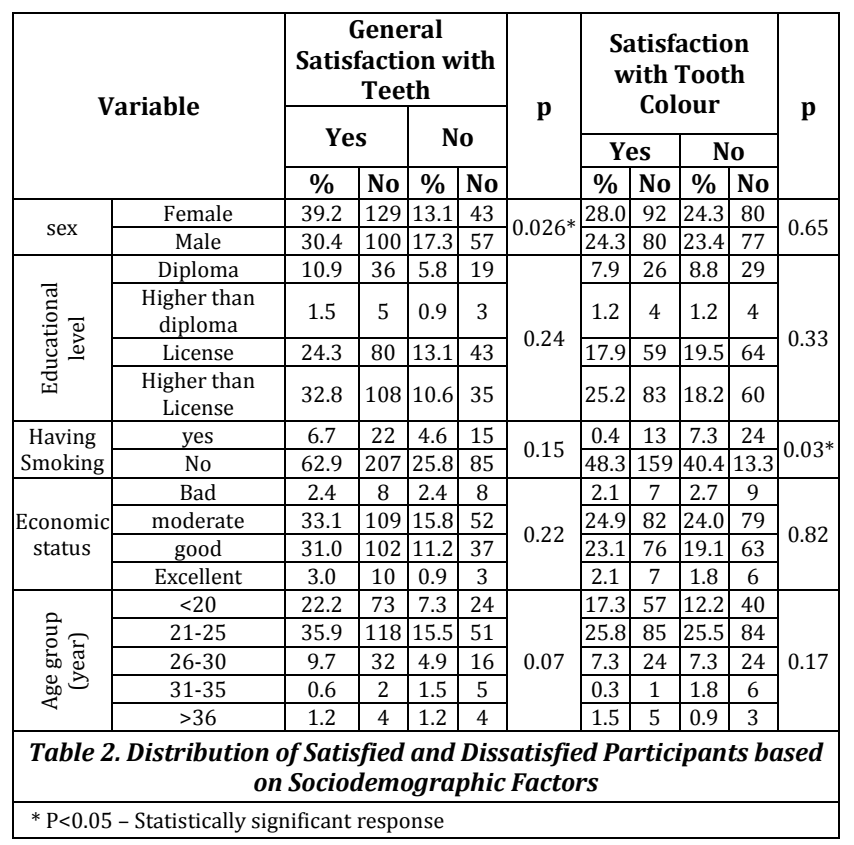

\begin{tabular}{|c|c|c|c|c|c|c|c|c|c|c|c|c|c|c|c|c|c|}
\hline \multirow{3}{*}{\multicolumn{2}{|c|}{ Variable }} & \multicolumn{4}{|c|}{\begin{tabular}{|c|} 
Orthodontic \\
Treatment \\
\end{tabular}} & \multicolumn{4}{|c|}{$\begin{array}{c}\text { Tooth } \\
\text { Whitening }\end{array}$} & \multicolumn{4}{|c|}{$\begin{array}{l}\text { Tooth } \\
\text { Crown }\end{array}$} & \multicolumn{4}{|c|}{ Denture } \\
\hline & & \multicolumn{2}{|c|}{ Yes } & \multicolumn{2}{|c|}{ No } & \multicolumn{2}{|c|}{ Yes } & \multicolumn{2}{|c|}{ No } & \multicolumn{2}{|c|}{ Yes } & \multicolumn{2}{|c|}{ No } & \multicolumn{2}{|c|}{ Yes } & \multicolumn{2}{|c|}{ No } \\
\hline & & $\%$ & No & $\%$ & No & $\%$ & No & $\%$ & No & $\%$ & No & $\%$ & No & $\%$ & No & $\%$ & No \\
\hline \multirow{2}{*}{ 离 } & Female & 20.1 & 66 & 32.2 & 106 & 32.5 & 107 & 19.8 & 365 & 21.0 & 69 & 31.3 & 103 & 6.1 & 20 & 46.2 & 2152 \\
\hline & Male & 21.0 & 69 & 26.7 & 88 & 26.7 & 96 & 18.5 & 561 & 17.9 & 59 & 29.8 & 98 & 8.2 & 273 & 39.5 & 5130 \\
\hline \multirow{4}{*}{ 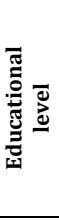 } & diploma & 7.3 & 24 & 9.4 & 31 & 10.3 & 34 & 6.4 & 21 & 7.0 & 23 & 9.7 & 32 & 2.7 & \begin{tabular}{l|l}
9 & 1 \\
\end{tabular} & 14.0 & 046 \\
\hline & \begin{tabular}{|c|} 
Higher \\
than \\
diploma
\end{tabular} & 1.2 & 4 & 1.2 & 4 & 2.1 & 7 & 0.3 & 1 & 1.5 & 5 & 0.9 & 3 & 0.3 & 1 & 2.1 & 7 \\
\hline & License & 17.6 & 58 & 19.8 & 65 & 25.8 & 85 & 11.6 & 638 & 18.5 & 61 & 18.8 & 62 & 8.8 & 292 & 28.6 & \begin{tabular}{|l|l|}
694 \\
\end{tabular} \\
\hline & $\begin{array}{c}\text { Higher } \\
\text { than } \\
\text { License }\end{array}$ & 14.9 & 49 & 28.6 & 94 & 23.4 & 77 & 20.1 & $1 \mid 66$ & 11.9 & 39 & 31.6 & 104 & 2.4 & 84 & 41.0 & 0135 \\
\hline \multirow{2}{*}{ 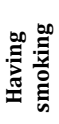 } & yes & 5.8 & 19 & 5.5 & 18 & 7.9 & 26 & 3.3 & 11 & 6.1 & 20 & 5.2 & 17 & 4.0 & 13 & 7.3 & 24 \\
\hline & no & D. & 16 & 3.3 & 176 & 53.8 & 177 & 3.0 & 115 & 32.8 & 108 & 55.9 & 184 & 10.3 & 347 & & 4258 \\
\hline \multirow{4}{*}{ 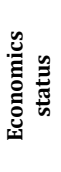 } & $\mathrm{Bad}$ & 1.8 & 6 & 3.0 & 10 & 2.4 & 8 & 2.4 & 8 & 1.2 & 4 & 3.6 & 12 & 1.2 & 4 & 3.6 & 12 \\
\hline & Moderate & 21.0 & 69 & 28.0 & 92 & 31.3 & 102 & 17.6 & 58 & 19.5 & 64 & 29.5 & 97 & 7.0 & $23 \mid$ & 41.9 & 9138 \\
\hline & Good & 16.7 & 55 & 25.5 & 84 & 25.8 & 85 & 16.4 & 4. 54 & 17.0 & 56 & 25.2 & 83 & 5.5 & 18 & 36.8 & 8121 \\
\hline & Excellent & 1.5 & 5 & 2.4 & 8 & 2.1 & 7 & 1.8 & 6 & 1.2 & 4 & 2.7 & 9 & 0.6 & 2 & 3.3 & 11 \\
\hline \multirow{5}{*}{ 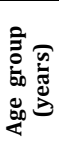 } & $<20$ & 12.5 & 41 & 17.0 & 56 & 18.8 & 62 & 10.6 & 35 & 12.2 & 40 & 17.3 & 57 & 4.3 & 142 & 25.2 & 283 \\
\hline & $21-25$ & 22.2 & 73 & 29.2 & 96 & 31.6 & 104 & 19.8 & 365 & 18.5 & 61 & 32.8 & 108 & 6.1 & 20 & & 3149 \\
\hline & $26-30$ & 4.9 & 16 & 9.7 & 32 & 8.5 & 28 & 6.1 & 20 & \begin{tabular}{|l|}
6.7 \\
\end{tabular} & 22 & 7.9 & 26 & 3.0 & 10 & 11.6 & \begin{tabular}{|l|l|}
638 \\
\end{tabular} \\
\hline & $31-35$ & 0.6 & 2 & 1.5 & 45 & 0.9 & 23 & 1.2 & 4 & 0.6 & 2 & 1.5 & 5 & 0.6 & 2 & 1.5 & 5 \\
\hline & $>36$ & 0.9 & 3 & 1.5 & 5 & 1.8 & 6 & 0.6 & 2 & 0.9 & 3 & 1.5 & 5 & 0.3 & 1 & 2.1 & 7 \\
\hline \multicolumn{18}{|c|}{$\begin{array}{l}\text { Table 3. Tendency to Various Types of Treatment for Dental Aesthetic } \\
\text { Improvement According to Sociodemographic Factors }\end{array}$} \\
\hline
\end{tabular}
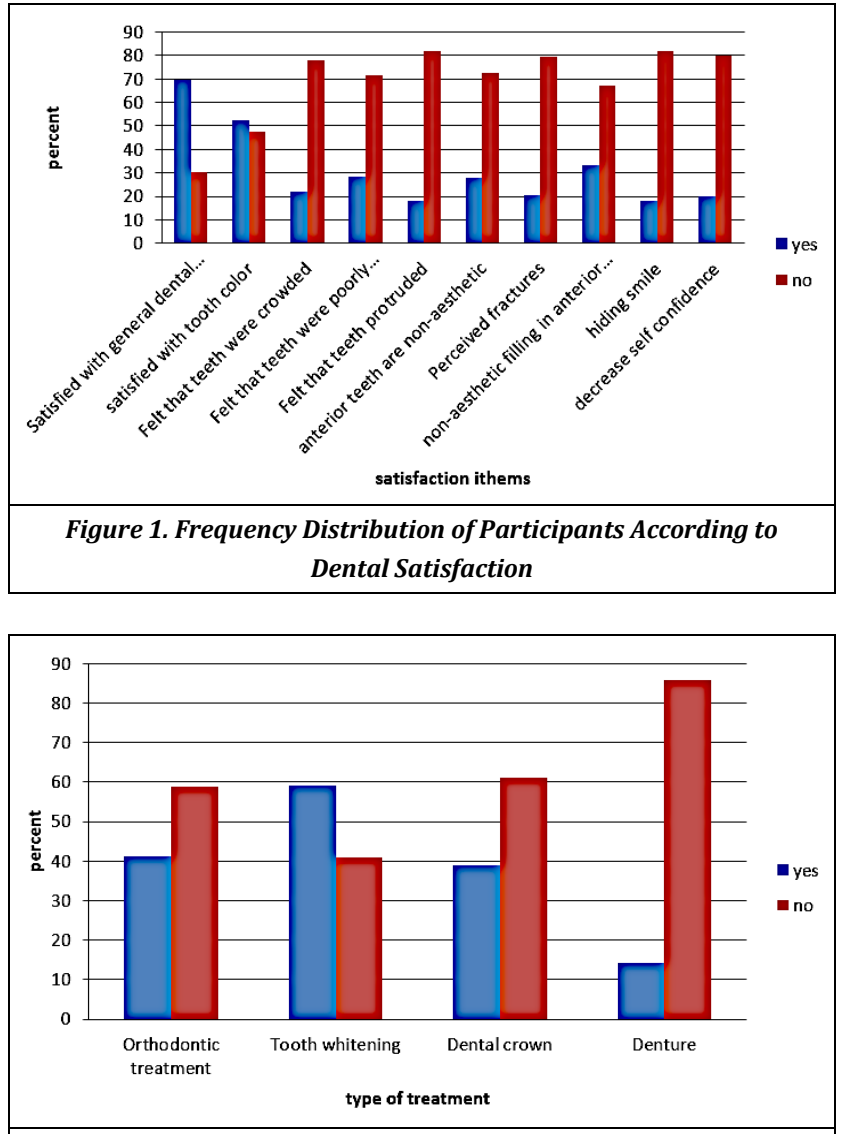

Figure 2. Participants' 'Desired Aesthetic Dental Treatments

As can be seen, there was a significant relationship between gender and overall satisfaction with dental appearance, as women were more satisfied with their teeth $(p=0.026)$. There was also a significant relationship between smoking and satisfaction with tooth colour, as smokers were more dissatisfied with their tooth colour $(p=0.03)$. A marginally significant relationship was also observed between age and the overall satisfaction with dental appearance, as people in the age group of 21-25 years were less satisfied in this respect $(p=0.07)$. Among the respondents, tooth whitening was the most preferred solution 203 (59.2\%) and using dentures was the least preferred solution $47(14.3 \%)$ for improving dental appearance.

The frequency of responses given to the questions about the inclination to use tooth crowns, dentures, braces, and whitening in different demographic groups are presented in Table 3. As can be seen, women were more inclined to use whitening and crowns and less inclined to use braces and dentures than men, but this difference was not statistically significant. Also, people in the age group of 21-25 years were more inclined to undergo whitening procedure than the other age groups. The overall satisfaction with dental appearance was found to significantly decrease with age.

\section{DISCUSSION}

The colour, shape, location, alignment, and occlusion of the teeth, especially the anterior teeth, have a profound impact on the overall appearance of the teeth.(2) In this study, 229 
[69.60\%] of the respondents were generally satisfied with their dental appearance. Of those satisfied with their dental appearance, 129 [39.2\%] were women and 100 [30.4\%] were men.

In a study by Lajnert et al.(13) on Caucasians in Croatia, $42.9 \%$ of men and $40.9 \%$ of women were satisfied with their dental appearance, which is less than what was observed in the present study. This difference can be attributed to the fact that Lajnert's study was focused on satisfaction with anterior teeth. Studies conducted in different countries have reported varying levels of satisfaction, for example, $42.2 \%$ in Malaysia $57.3 \%$ in Turkey,(2) $65 \%$ in Palestine,(14) $65.5 \%$ in Jordan(15) and $76 \%$ in the United Kingdom.(16)

As can be seen, satisfaction rates reported in all of these studies are higher than ours. Satisfaction with dental appearance can be influenced by many factors, most notably personal preferences and cultural and socioeconomic elements, so much so that an appearance deemed beautiful by one person or culture can be seen as the opposite by another.(2)

In this study, a statistically significant relationship was observed between gender and overall satisfaction with dental appearance. More specifically, a higher percentage of men were dissatisfied with their dental appearance than women. This is inconsistent with the findings of Al-Shahrani et al.(17) and Al-Omiri et al,(5) where women were more dissatisfied with their dental appearance.

It has been suggested that dental appearance is more important to men,(18) but women tend to be more satisfied with the overall appearance of their teeth.(3) It should be noted that satisfaction with dental appearance can be highly associated with one's preferences and perceptions of beauty. In the present study, 172 [52.3\%] of the respondents were satisfied with their tooth colour. In the studies of Lajnert et al,(13) Maghaireh et al,(10) and Al-Zarea et al,(19) the rate of satisfaction with tooth colour has been $36.6 \%, 66.3 \%$, and $43.1 \%$ respectively. It has been shown that tooth colour is the primary cause of dissatisfaction with dental appearance.(2)

In our study, dissatisfaction with tooth colour was higher in the age group of 21-25 years, but the difference with other age groups was not statistically significant. In other studies, it has been suggested that dissatisfaction with tooth colour depends on age.(20)

In this study, people with a bachelor's or higher degree were more satisfied with their tooth colour. This is consistent with the reports of Xiao(21) and Akarslan et al.(2)

It has been argued that higher satisfaction with tooth colour in people with higher academic education may be influenced by higher self-esteem. ${ }^{(21,2)}$

In the present study, there was a statistically significant relationship between smoking and satisfaction with tooth colour (Smokers were less satisfied with the colour of their teeth). This is because tooth discolouration is a major side effect of smoking and can, therefore, have a deep impact on people's satisfaction with their tooth colour.

In this study, 72 [22.9\%] of the people stated that they have tooth crowding. In the study of Al-Zarea,(19) $25 \%$, and in the study of Tin-Oo(11) $26.4 \%$ of patients believed that they had tooth crowding, which are roughly consistent with our finding. In our study, 93 [28.3\%] of the respondents stated that they have malocclusion. The corresponding figures in the studies of Al-Zarea( ${ }^{(19)}$ and Tin-Oo(11) were $41.7 \%$ and $32.3 \%$ respectively. Of the subjects of this study, $18.2 \%$ believed that they had prominent teeth, which is close to the figures reported by Al-Zarea (17.7\%)(19) and Tin-Oo et al. (23.4\%). (11)

Malocclusion has a great impact on the overall appeal of the face and therefore on how people are perceived in society. (22, 23)

In this study, 109 [33.1\%] of the respondents stated that had unattractive fillings in their anterior teeth and 68 [19.7\%] stated that had fractures in these teeth. These figures were respectively $16.4 \%$ and $23.2 \%$ in the study of $\mathrm{Al}$ Zarea,(19) $30.6 \%$ and $15.3 \%$ in the study of Tin-Oo,(11) and $9 \%$ and $13 \%$ in the study of Subait et al.(24)

Our study found a significant relationship between age and having cracks, fractures and unattractive filling in anterior teeth, as this percentage was higher in the age group of 21-25 years. The study of Al-Zarea(19) also reported a significantly higher rate of unattractive filling, cracks, and fractures in young people than in the elderly. In one study, the rate of satisfaction with anterior teeth restorations in Jordanian patients was $67.6 \%$. But, for the same group, the rate of anterior teeth restorations that were seen as satisfactory by the clinician was $43.8 \%$. $^{(8)}$ It has been shown that anterior teeth are an essential component of a beautiful smile.(25)

In this study, 135 [41.1\%] of the respondents were inclined to undergo orthodontic treatment and this rate was almost equal among men and women. In the study of Alsubait et al,(24) $18.2 \%$ of people were willing to undergo orthodontic treatment. In the study of Maghaireh et al,(10) women were significantly more inclined to receive orthodontic treatment than men.

In our study, 203 [59.2\%], 128 [38.9\%], and 47 [14.3\%] of the respondents were inclined to undergo tooth whitening, crown placement, and denture placement procedures to improve their dental appearance. The reason for the lower tendency to use dentures may be the larger size of the younger population in our study. The women were more inclined to undergo crown placement and whitening procedures, but the difference was not significant. In the study of Al-Zarea. (19) $80.9 \%$ of people proffered the whitening procedure. In the studies of Maghaireh et al.(10) Akarslan et al.(9) and Tin-Oo et al. (11) this figure was 55.3\%, $49.0 \%$, and $48.1 \%$ respectively. In other studies, the teeth whitening procedure has been the most preferred cosmetic dental treatment in Riyadh, London, and Malaysia.(11,24,26) The observed difference in our findings can be attributed to the differences in the studied population and the methods of evaluation of satisfaction with dental appearance. It has been shown that people generally prefer pearly white teeth, and therefore, tooth colour is one of the important determinants of people's satisfaction with the appearance of their teeth.(1,2) Having white teeth have been shown to be positively correlated with increased sociability, mental ability, psychological adaptability, and communication skills.(4) Also, it has been shown that having untreated tooth decay, poor anterior tooth restoration, and lack of anterior teeth are correlated with dissatisfaction with dental appearance. $(2,3,5,6)$

In this study, 60 [18.2\%] of the respondents stated that they hide their smile and 66 [20.0\%] of them had decreased self-esteem because of their teeth. In a study in Saudi Arabia, $40.5 \%$ of high school girls were often or occasionally hiding 
their smile.(24) In another study, the most important reason for asking for a fixed prosthesis was to hide the teeth while smiling. In this study, women were more inclined to hide their smile than men. This study reported that concealing teeth while smiling, teeth crowding and misalignment from the patient's view and low satisfaction with dental appearance were all important factors in choosing orthodontic treatment.(27)

The regression analysis showed no significant relationship between gender and the score of overall satisfaction with dental appearance. This can be because with the growing pervasiveness of social media and increased advertisement of solutions to have a beautiful smile, men and women are equally affected by the external factors, which has resulted in a limited difference in their overall satisfaction with their teeth.

In the regression analysis, a significant relationship was found between the mean age of the respondents and the mean score of satisfaction with dental appearance. This is consistent with the findings of Lajnert(13) and Alkhatib,(16) which reported that older people were less satisfied with their dental appearance. Older people usually have more dental restorations, wear, and discolouration, which can affect their satisfaction with their teeth.

In this study, smokers were more satisfied with their dental appearance. This may be because smokers know that smoking is one of the major causes of tooth discolouration and therefore attribute any dental unattractiveness to tobacco use.

Many factors may affect patients' satisfaction with the beauty of their teeth. Some of these factors could be partially interrelated and complement or even reduce each other. Since teeth colour, shape, size, and alignment are the factors that determine people's satisfaction with their dental appearance, understanding the current prevalence of dissatisfaction with dental appearance and demand for cosmetic treatments can guide the strategies for cosmetic dental interventions. Since the majority of the respondents were young, the results may not be generalizable to a population with a higher age range.

\section{CONCLUSIONS}

Tooth whitening was the most preferred method for improving dental appearance. Older people were significantly less satisfied with their dental appearance and people with better economic conditions were significantly more satisfied with their dental appearance. To ensure patient satisfaction with cosmetic treatments, clinicians should gain a better understanding of patients' perceptions, desires, and apprehensions in regard to dental appearance.

\section{REFERENCES}

[1] Qualtrough AJ, Burke FJ. A look at dental esthetics. Quintessence International 1994;25(1):7-14.

[2] Akarslan ZZ, Sadik B, Erten H, et al. Dental aesthetic satisfaction, received and desired dental treatments for improvement of esthetics. Indian J Dent Res 2009;20(2):195-200.

[3] Samorodnitzky-Naveh GR, Geiger SB, Levin L. Patients' satisfaction with dental esthetics. J Am Dent Assoc 2007;138(6):805-8.

[4] Kershaw S, Newton JT, Williams DM. The influence of tooth colour on the perceptions of personal characteristics among female dental patients: comparisons of unmodified, decayed and 'whitened' teeth. British Dental Journal 2008;204(5):E9.

[5] Al-Omiri MK, Karasneh JA, Lynch E, et al. Impacts of missing upper anterior teeth on daily living. International Dental Journal 2009;59(3):127-32.

[6] Gerritsen A, Sarita P, Witter DJ, et al. Esthetic perception of missing teeth among a group of Tanzanian adults. The International Journal of Prosthodontics 2008;21(2):16973.

[7] Ajayi EO. Dental aesthetic self-perception and desire for orthodontic treatment among school children in Benin City, Nigeria. Nig Q J Hosp Med 2011;21(1):45-9.

[8] Albashaireh ZS, Alhusein AA, Marashdeh MM. Clinical assessments and patient evaluations of the esthetic quality of maxillary anterior restorations. Int J Prosthodont 2009;22(1):65-71.

[9] Hamamci N, Basaran G, Uysal E. Dental Aesthetic Index scores and perception of personal dental appearance among Turkish university students. Eur J Orthod 2009;31(2):168-73.

[10] Maghaireh GA, Alzraikat H, Taha NA. Satisfaction with dental appearance and attitude toward improving dental esthetics among patients attending a dental teaching center. J Contemp Dent Pract 2016;17(1):16-21.

[11] Tin-Oo MM, Saddki N, Hassan N. Factors influencing patient satisfaction with dental appearance and treatments they desire to improve aesthetics. BMC Oral Health 2011;11:6.

[12] Hassel AJ, Wegener I, Rolko C, et al. Self-rating of satisfaction with dental appearance in an elderly German population. Int Dent J 2008;58(2):98-102.

[13] Lajnert V, Pavičić DK, Pezo H, et al. Patients' general satisfaction with the appearance of anterior maxillary teeth. Vojnosanit Pregl 2017;74(6):520-5.

[14] Younis A, Al-Omiri MK, Hantash RO, et al. Relationship between dental impacts on daily living, satisfaction with the dentition and personality profiles among a Palestinian population. Odontostomatol Trop 2012;35(138):21-30.

[15] Karasneh J, Al-Omiri MK, Al-Hamad KQ, et al. Relationship between patient's oral health-related quality of life, satisfaction with dentition and personality profiles. J Contemp Dent Pract 2009;10(6):E049-56.

[16] Alkhatib MN, Holt R, Bedi R. Age and perception of dental appearance and tooth colour. Gerodontology 2005;22(1):32-6.

[17] Al-Shahrani I. Self-perception of personal dental appearance among students of King Khaled University Abha, Saudi Arabia. Eur J Gen Dent 2014;3(3):181-4. 
[18] Al-Habahbeh R, Al-Shammout R, Al-Jabrah 0, et al. The effect of gender on tooth and gingival display in the anterior region at rest and during smiling. Eur J Esthet Dent 2009;4(4):382-95.

[19] Al-Zarea BK. Satisfaction with appearance and the desired treatment to improve aesthetics. Int J Dent 2013;2013:912368.

[20] Vallittu PK, Vallittu AS, Lassila VP. Dental aesthetics: a survey of attitudes in different groups of patients. J Dent 1996;24(5):335-8.

[21] Xiao J, Zhou XD, Zhu WC, et al. The prevalence of tooth discolouration and the self-satisfaction with tooth colour in a Chinese urban population. Journal of Oral Rehabilitation 2007;34(5):351-60.

[22] Karunakaran T, Gilbert D, Asimakopoulou K, et al. The influence of visible dental caries on social judgements and overall facial attractiveness amongst undergraduates. Journal of Dentistry 2011;39(3):212-7.

[23] Somani A, Newton JT, Dunne S, et al. The impact of visible dental decay on social judgements: comparison of the effects of location and extent of lesion. International Dental Journal 2010;60(3):169-74
[24] Alsubait A, Ali A, Alwakeel RS, et al. Satisfaction, awareness and attitude about oral aesthetics among female high school students in Riyadh, Saudi Arabia: a cross-sectional study. Journal of Oral \& Dental Health 2017;1(1):1-5.

[25] Sarver DM. The importance of incisor positioning in the esthetic smile: the smile arc. Am J Orthod Dentofacial Orthop 2001;120(2):98-111.

[26] Al-Shiekh L, El-Dien MM, Abd El-Raheem M, et al. Evaluation of dental students' oral hygiene attitude and behavior using HU-DBI in Sudan. S-PPJ 2014;1(1): e00040.

[27] Grzić R, Spalj S, Lajnert V, et al. Factors influencing a patient's decision to choose the type of treatment to improve dental esthetics. Vojnosanit Pregl 2012;69(11):978-85. 